\title{
Effects of hyperinflation on the oxygen pulse as a marker of cardiac performance in COPD
}

\author{
C. Vassaux*, L. Torre-Bouscoulet*\#, S. Zeineldine*, F. Cortopassi*, H. Paz-Díaz*, \\ B.R. Celli* and V.M. Pinto-Plata*
}

ABSTRACT: A decreased inspiratory capacity (IC)/total lung capacity (TLC) ratio is associated with dynamic hyperinflation and decreased exercise capacity. The present authors hypothesised that static (Iow IC/TLC) and dynamic hyperinflation impair cardiac function as assessed by oxygen pulse at rest and during cardiopulmonary exercise testing (CPET).

Lung function, body mass index, hand grip strength and CPET parameters were measured (oxygen uptake $\left(\mathrm{mL} \cdot \mathrm{kg}^{-1} \cdot \mathrm{min}^{-1}\right)$ and oxygen pulse $\left(\mathrm{mL} \cdot\right.$ beat $\left.\left.^{-1}\right)\right)$ in 87 chronic obstructive pulmonary disease (COPD) patients (American Thoracic Society/European Respiratory Society/ Global Initiative for Chronic Obstructive Lung Disease stage 3-4) and 46 controls. The patients were divided into those with IC/TLC $>25 \%$ or $\leqslant 25 \%$.

The IC/TLC ratio at rest and at peak exercise was associated significantly with oxygen pulse. Patients with IC/TLC $\leqslant 25 \%(n=45)$ had significantly lower exercise capacity, peak oxygen pulse, peak minus baseline oxygen pulse, peak IC, peak IC/TLC ratio and \% change from baseline to peak IC/TLC ratio compared with patients with IC/TLC $>25 \%$ and controls. During CPET, the oxygen pulse was lower at iso-work in patients with IC/TLC $\leqslant 25 \%$ than in those with IC/TLC $>25 \%$.

Resting hyperinflation (inspiratory capacity/total lung capacity) is associated with lower oxygen pulse, peak exercise inspiratory capacity/total lung capacity and exercise capacity in patients with severe chronic obstructive pulmonary disease. The present results support an interaction between hyperinflation and decreased cardiac function that may contribute to exercise limitation in these patients.

KEYWORDS: Chronic obstructive pulmonary disease, exercise, inspiratory capacity, inspiratory capacity to total lung capacity ratio, oxygen pulse, oxygen uptake

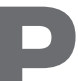

atients with chronic obstructive pulmonary disease (COPD) have limited exercise tolerance [1]. The cause for this limitation appears to be multifactorial [2-7]. The identification of factors that determine this constraint is critical for the development of different therapeutic strategies that could improve exercise performance, quality of life and, possibly, survival [8].

Several studies have shown that dyspnoea and exercise limitation in COPD are related to increased end-expiratory lung volume (EELV) and limited ventilatory reserve $[3,9]$. Treatment with bronchodilators [10,11] and lung volume reduction surgery (LVRS) [8] delay the onset of dyspnoea and increase exercise endurance in close relation to the improvement of operational lung volume secondary to decreases in EELV.
Other physiological contributors to the ventilatory limitation during exercise include reduced maximal voluntary ventilation [12, 13], forced expiratory volume in one second (FEV1) [14] and diffusion capacity $(D \mathrm{~L}, \mathrm{CO})[15]$.

Less explored is the role of cardiovascular factors that may also contribute to exercise limitation in these patients [16]. BUTLER et al. [17] studied patients with severe COPD and normal controls during cardiopulmonary exercise testing (CPET) and resting hyperventilation, using central venous catheter measurements to determine cardiac performance. The study suggested that the increment in pulmonary capillary wedge pressure and intracardiac pressures partially resulted from increased transmural pressure on the heart due to the mechanical constraints of hyperinflated lungs. JÖRGENSEN and co-workers

\section{AFFILIATIONS}

*Division of Pulmonary, Critical Care and Sleep Medicine, Caritas St Elizabeth's Medical Center, Tufts University School of Medicine, Boston, MA, USA.

"Departamento de Fisiología, Instituto Nacional de Enfermedades Respiratorias, México City, Mexico.

\section{CORRESPONDENCE}

V.M. Pinto-Plata

Caritas St Elizabeth's Medical Center 736 Cambridge

Boston

02135

MA

USA 02135

Fax: 16175627756

E-mail:vpinto@copdnet.org

Received:

November 132007

Accepted after revision:

May 292008

STATEMENT OF INTEREST

None declared. 
$[18,19]$ studied patients with severe emphysema using direct haemodynamic measurements before and after LVRS and magnetic resonance imaging to determine cardiac dimensions and intrathoracic blood volume (ITBV). Improvement in lung volume dimension and filling was documented with concomitant improvement in function after LVRS. A reduced biventricular end-diastolic volume due to reduced ITBV was also reported and hyperinflation (not measured) was hypothesised to be the responsible mechanism. These studies suggest that hyperinflation may affect exercise performance in patients with severe COPD by generating intrathoracic hypovolaemia and compromising cardiovascular performance.

Oxygen pulse is a noninvasive and reliable method used to estimate stroke volume and cardiac function [20-24]. The oxygen pulse is calculated by dividing the oxygen uptake $\left(V^{\prime} \mathrm{O}_{2}\right)$ by the cardiac frequency $(f \mathrm{C})$, assuming that the arteriovenous difference of oxygen is normal, as appears to be the case in patients with COPD $[4,25]$.

Inspiratory capacity (IC)/total lung capacity (TLC) ratio $\leqslant 25 \%$ is a marker of hyperinflation and mortality [26] and is associated with altered exercise capacity in patients with COPD [27]. The reason for these findings is not clear, but they could be partially explained by the effect of hyperinflation on cardiovascular function $[17,28]$. To test this hypothesis, the present authors studied the association between IC/TLC ratio and oxygen pulse at rest, during exercise and at peak exercise in patients with severe COPD. It was hypothesised that patients with IC/TLC $\leqslant 25 \%$ would have lower resting oxygen pulse, and that at similar work rate it would fail to rise appropriately during exercise compared with patients with IC/TLC $>25 \%$ and subjects of similar age without COPD.

\section{METHODS AND MATERIALS}

Patients and normal individuals were prospectively recruited as part of a cohort study of patients with COPD followed at Caritas St Elizabeth's Medical Center (Boston, MA, USA). Stable patients with stages 3 and 4 COPD (American Thoracic Society (ATS)/European Respiratory Society (ERS)/Global Initiative for Chronic Obstructive Lung Disease) were included, along with control group (FEV1/forced vital capacity $>70 \%$ and FEV1 $>80 \%$ predicted) of similar age. The institutional review board approved the study and all patients gave informed consent. Participants (patients with COPD and control subjects) were recruited via outpatient clinic, local press advertisement or peer referral.

Spirometry, lung volumes by plethysmography and singlebreath DL,CO were performed according to ATS/ERS standards [29-31]. The dyspnoea level was measured using the Modified Medical Research Council (MMRC) scale. Subjects also performed a 6-min walk distance (6MWD) test following the ATS guidelines [32]. The maximal grip strength for each hand was averaged from three measurements made using a dynamometer (Jamar; Asimow Enginering Co., Santa Monica, CA, USA) with the hand unsupported [33].

CPET was performed following ATS/American College of Chest Physicians standards [34] using a cycle ergometer, with gas exchange measured using a metabolic cart (V Max; Sensormedics, Yorba Linda, CA, USA). The protocol included three stages: resting, warm-up and exercise (symptom limited exercise test with increments of $\left.16 \mathrm{~W} \cdot \mathrm{min}^{-1}\right)$. During every stage, while breathing room air, $V^{\prime} \mathrm{O}_{2}$, carbon dioxide production, $f C$, blood pressure, respiratory rate, oxygen saturation and tidal volume were continuously measured. The exercise variables analysed were: maximal power achieved, maximal $V^{\prime} \mathrm{O}_{2}$, maximal $\mathrm{f} \mathrm{C}$, oxygen pulse, $\Delta \mathrm{O}_{2}$ pulse (oxygen pulse at peak exercise minus baseline oxygen pulse), breathing reserve, heart reserve, $\Delta V^{\prime} \mathrm{O}_{2} / \Delta$ work, $\Delta f \mathrm{C} / V^{\prime} \mathrm{O}_{2}$, dead space, IC was measured each minute during the test and the IC/TLC and $\triangle \mathrm{IC} / \mathrm{TLC}$ (baseline IC/TLC minus peak IC/TLC) were calculated using the plethysmographic TLC value. Arterial blood gas values obtained at rest and at peak exercise were used to determine the gas exchange parameters. The peak exercise arterial blood gas samples from seven patients contained clots and samples could not be obtained from three. The patients were encouraged to cycle to the point of discomfort or exhaustion. The test was interrupted if an abnormal electrocardiogram, a systolic blood pressure $>220 \mathrm{mmHg}$ or diastolic blood pressure $>120 \mathrm{mmHg}$ was measured. All exercise parameters were calculated using formulae described by WASSERMAN et al. [20].

\section{Statistical analysis}

Normality in the distribution of the data for each variable was explored using Skewness-Kurtosis tests. For variables with normal distribution the data are expressed as mean \pm SD and unpaired t-tests were used. Data not normally distributed are presented in the form of median and interquartile range and differences between groups were explored using MannWhitney, Kruskall-Wallis and Wilcoxon signed-rank tests. Iso-time was defined as that point during the exercise that was common for all patients and controls. Simple linear regressions, with oxygen pulse as the dependent variable, were explored. Those variables significantly associated with oxygen pulse were used in a multivariate analysis. The acceptable level of statistical significance for independent comparisons was $p<0.05$. For multiple comparisons, the cut-off point for the $p-$ value was adjusted using the Bonferroni correction and $\mathrm{p}<0.005$ was considered significant.

\section{RESULTS}

The clinical and physiological characteristics of the participants are summarised in table 1 . The control subjects had normal spirometry and were well matched for age, sex and anthropometrics with the COPD patients. The COPD group had severe obstruction (median FEV1 34\% pred) and significantly lower IC/TLC ratio and 6MWD compared with controls.

Table 2 shows that the exercise capacity and peak oxygen were decreased in COPD patients compared with controls. The IC/ TLC ratio did not change during exercise in the control group but decreased significantly in the COPD group $(\mathrm{p}<0.001)$. The oxygen content at peak exercise in the COPD group was $17.9 \pm 2 \mathrm{~mL}$.

There was a significant correlation for the entire group between IC/TLC ratio and resting oxygen pulse $(\mathrm{r}=0.44$; $\mathrm{p}<0.001)$, which increased with peak exercise oxygen pulse $(\mathrm{r}=0.65 ; \mathrm{p}<0.001$; fig. 1$)$. In the COPD group, the correlation coefficient was $0.46(p<0.001)$. The association was still maintained $(\mathrm{r}=0.41 ; \mathrm{p}=0.007)$ in 64 patients whose resting 


\begin{tabular}{|c|c|c|c|}
\hline \multirow[t]{2}{*}{ TABLE 1} & \multicolumn{3}{|c|}{$\begin{array}{l}\text { Clinical and physiological characteristics of all } \\
\text { subjects participating in the study }\end{array}$} \\
\hline & Control & COPD $^{\#}$ & $p$-value \\
\hline Subjects n & 46 & 87 & \\
\hline Age yrs & $63 \pm 7$ & $65 \pm 9$ & $0.1^{\circ}$ \\
\hline Male/female \% & $54 / 46$ & $61 / 39$ & 0.4 \\
\hline BMI $\mathbf{k g} \cdot \mathrm{m}^{-2}$ & 27 (24-31) & $26(23-31)$ & $0.2^{+}$ \\
\hline FFM kg & $49(42.1-66)$ & $56.1(46.6-66.1)$ & $0.4^{+}$ \\
\hline MMRC & $0(0-0)$ & $2(2-3)$ & $<0.001^{+}$ \\
\hline 6MWD m & $536 \pm 92$ & $370 \pm 96$ & $<0.001^{\circ}$ \\
\hline FEV $1 \%$ pred & $93(86-98)$ & $34(28-40)$ & $<0.001^{+}$ \\
\hline FVC \% pred & $99 \pm 13$ & $66 \pm 17$ & $<0.001^{\natural}$ \\
\hline TLC \% pred & $94(86-109)$ & $129(113-141)$ & $<0.001^{+}$ \\
\hline RV \% pred & $94(70-112)$ & 208 (172-259) & $<0.001^{+}$ \\
\hline IC L & $2.34(1.79-2.63)$ & $1.65(1.28-2.01)$ & $<0.001^{+}$ \\
\hline IC/TLC \% & $44(41-56)$ & 25 (19-29) & $<0.001^{+}$ \\
\hline \multicolumn{4}{|c|}{ 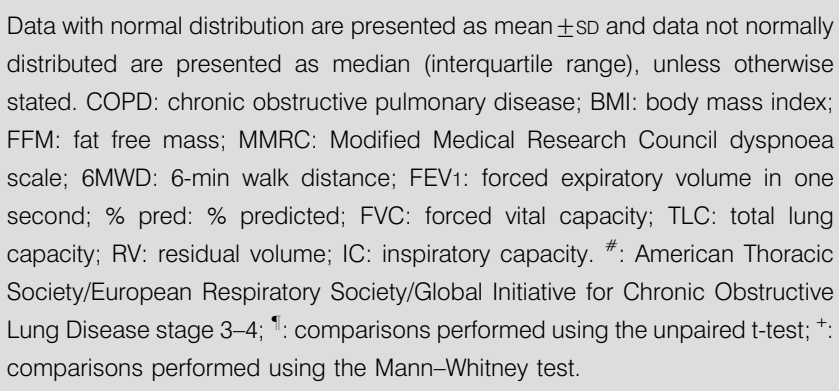 } \\
\hline
\end{tabular}

and peak arterial oxygen partial pressure $\left(\mathrm{Pa}_{2} \mathrm{O}_{2}\right)$ was $>55 \mathrm{mmHg}(>7.3 \mathrm{kPa})$. There was a significant and inverse correlation $(\mathrm{r}=-0.30 ; \mathrm{p}<0.001)$ between the change in IC and the change in oxygen pulse from rest to peak exercise (fig. 2). There was also a direct correlation between absolute IC and oxygen pulse at iso-work (fig. 3).

The COPD patients were then divided into those with IC/TLC $\leqslant 25 \%(n=45)$ and $>25 \%(n=42)$. The general characteristics of these groups are shown in table 3 . Patients with IC/TLC $\leqslant 25 \%$ had lower fat free mass (FFM), 6MWD and hand grip force, compared with patients with IC/TLC $>25 \%$.

The exercise parameters in the control group and patients with low or high IC/TLC are presented in table 4. Patients with IC/ TLC $\leqslant 25 \%$ reached a lower exercise capacity, peak oxygen pulse, peak IC, peak IC/TLC ratio and $\triangle \mathrm{IC} / \mathrm{TLC}$ compared with patients with IC/TLC $>25 \%$. The work in watts was significantly associated with the $\mathrm{O}_{2}$ pulse $(\mathrm{r}=0.87 ; \mathrm{p}<0.001)$ and with IC/TLC $(\mathrm{r}=0.69 ; \mathrm{p}<0.001)$. More patients reached early anaerobic threshold in the low IC/TLC group (78\% versus $45 \% ; \mathrm{p}<0.001)$ with a trend toward an earlier anaerobic threshold in the low IC/TLC group $(\mathrm{p}=0.05)$ compared with the high IC/TLC group.

The results of the multivariate analysis with oxygen pulse at peak exercise as the dependent variable is presented in table 5. Body mass index, IC/TLC (\%), FEV1 (\% pred) and hand grip force $(\mathrm{kg})$ were significantly related to peak oxygen pulse. MMRC and DL,CO (\%) were also tested but failed to show any

\begin{tabular}{|c|c|c|c|}
\hline \multirow[t]{2}{*}{ TABLE 2} & \multicolumn{3}{|c|}{$\begin{array}{l}\text { Cardiopulmonary exercise test results in controls } \\
\text { and in patients with chronic obstructive } \\
\text { pulmonary disease (COPD) }\end{array}$} \\
\hline & & Control group $\#$ & COPD \\
\hline \multicolumn{2}{|c|}{ Exercise power $\mathrm{W}$} & $115(97-154)$ & $60(47-85)^{+}$ \\
\hline \multicolumn{4}{|l|}{$\mathrm{V}^{\prime} \mathrm{O}_{2}$} \\
\hline \multicolumn{2}{|c|}{ Baseline L·min ${ }^{-1}$} & $0.255(0.207-0.297)$ & $0.21(0.164-0.273)^{+}$ \\
\hline \multicolumn{2}{|c|}{ Maximal L $\cdot \min ^{-1}$} & $1.521(1.239-2.04)$ & $0.673(0.506-1.014)^{+}$ \\
\hline \multicolumn{2}{|c|}{ Maximal $\mathrm{mL} \cdot \mathrm{kg}^{-1} \cdot \mathrm{min}^{-1}$} & $20(16-26)$ & $10(7-12)^{+}$ \\
\hline \multicolumn{4}{|c|}{ fc } \\
\hline \multicolumn{2}{|c|}{ Baseline beats $\cdot \mathrm{min}^{-1}$} & $73 \pm 10$ & $87 \pm 14^{\S}$ \\
\hline \multicolumn{2}{|c|}{ Maximal beats $\cdot \min ^{-1}$} & $139 \pm 20$ & $121 \pm 16^{\S}$ \\
\hline \multicolumn{4}{|c|}{ Oxygen pulse } \\
\hline \multicolumn{2}{|c|}{ Baseline $\mathrm{mL} \cdot$ beat $^{-1}$} & $3.5 \pm 0.9$ & $2.5 \pm 0.8^{5}$ \\
\hline \multicolumn{2}{|c|}{ Peak mL-beat ${ }^{-1}$} & $10(8-14)$ & $6(4-8)^{+}$ \\
\hline \multicolumn{2}{|c|}{ Maximal V'E/MVV \% } & $61 \pm 21$ & $82 \pm 14^{\S}$ \\
\hline \multicolumn{4}{|l|}{ IC } \\
\hline \multicolumn{2}{|l|}{ Baseline L } & $2.37 \pm 0.64$ & $1.73 \pm 0.59^{5}$ \\
\hline \multicolumn{2}{|l|}{ Peak L } & $2.35 \pm 0.67$ & $1.26 \pm 0.41^{\S}$ \\
\hline \multicolumn{4}{|l|}{ IC/TLC } \\
\hline \multicolumn{2}{|l|}{ Baseline \% } & $44(41-50)$ & $25(19-29)^{+}$ \\
\hline \multicolumn{2}{|l|}{ Peak \% } & $45(38-50)$ & $18(14-22)^{+}$ \\
\hline
\end{tabular}

Data with normal distribution is presented as mean $\pm S D$ and data not normally distributed is presented as median (interquartile range). $\mathrm{V}^{\prime} \mathrm{O}_{2}$ : oxygen uptake; fC: cardiac frequency; $V^{\prime} E$ : minute ventilation; MVV: maximal voluntary ventilation; IC: inspiratory capacity; TLC: total lung capacity. ": $n=46$; American Thoracic Society/European Respiratory Society/Global Initiative for Chronic Obstructive Lung Disease stage $3-4, n=87 ;^{+}$: comparisons performed using the unpaired t-test; ${ }^{\text {s. }}$ : comparisons performed using the Mann-Whitney test. $p<0.001$ for all variables.

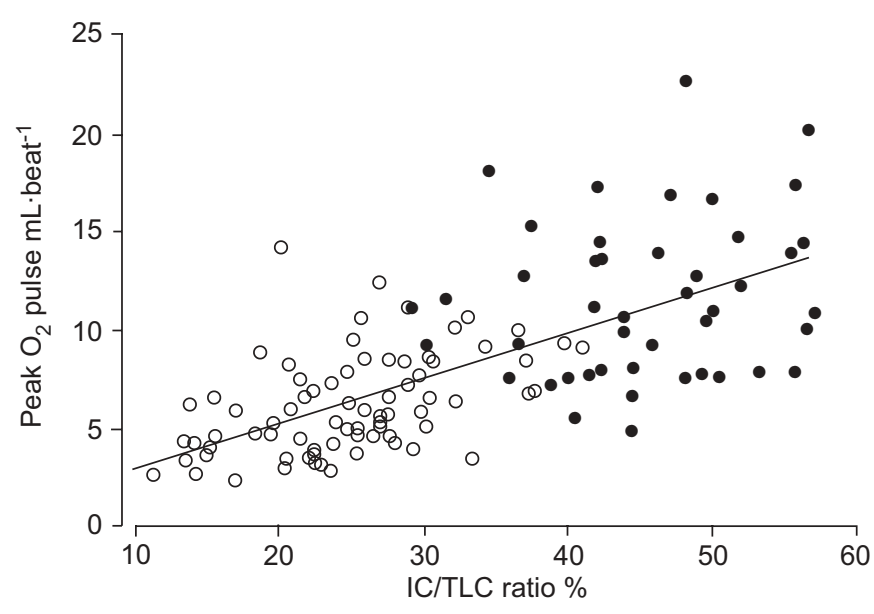

FIGURE 1. Relationship between static hyperinflation as expressed by the inspiratory capacity (IC)/total lung capacity (TLC) ratio and the oxygen pulse at peak of exercise in patients with chronic obstructive pulmonary disease $(\bigcirc)$ and controls -). A significant correlation was found $(r=0.95 ; p=0.001)$ 


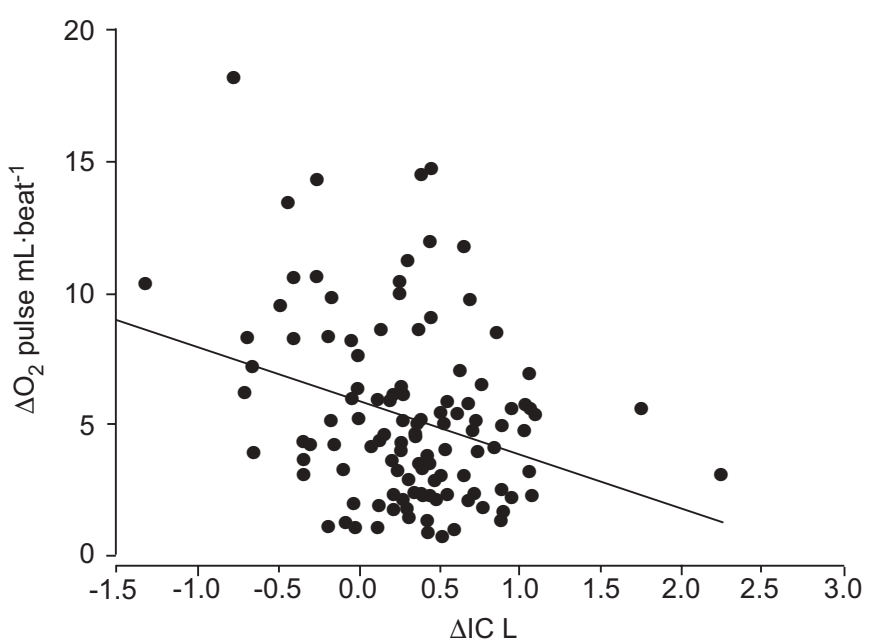

FIGURE 2. Relationship between change in inspiratory capacity $(\triangle I C)$ and change in oxygen pulse $\left(\triangle \mathrm{O}_{2}\right)$ from rest to peak exercise. A significant correlation was found $(r=-0.30 ; p<0.001)$

significant contribution to the model. The model explains $60 \%$ of the oxygen pulse variance.

Figure 4 shows that the baseline oxygen pulse, peak oxygen pulse and $\Delta \mathrm{O}_{2}$ pulse were significantly lower in the IC/TLC $\leqslant 25 \%$ group compared with the IC/TLC $>25 \%$ group and the control group $(\mathrm{p}<0.0001)$.

To determine whether the lower oxygen pulse was related to reduced exercise duration in patients with lower IC/TLC, changes in $f C, V^{\prime} \mathrm{O}_{2}$ and oxygen pulse were studied at iso-time (fig. 5). The oxygen pulse was significantly lower in the patients with the lowest IC/TLC at every exercise workload. The difference was due to a faster $f C$ and lower oxygen uptake.

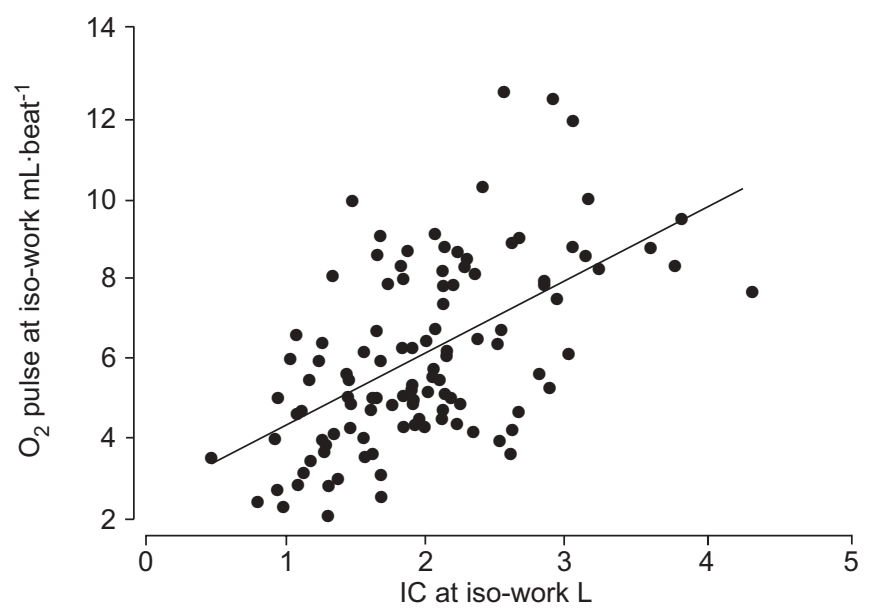

FIGURE 3. Relationship between inspiratory capacity (IC) and oxygen pulse at the same workload. A significant correlation was found $(r=0.56$; $p<0.00001)$

\section{DISCUSSION}

The most important finding in the present study of patients with severe COPD is the direct association between IC/TLC at rest and exercise with the oxygen pulse, a surrogate marker of cardiac function. The most hyperinflated patients had lower oxygen pulse at a similar exercise level than the patients with less hyperinflation. These observations support the concept that resting and dynamic hyperinflation may exert an important detrimental effect on cardiac function and play a role in the reduced exercise performance of patients with severe COPD. In addition, the baseline and peak exercise IC/ TLC were found to be equally associated with changes in oxygen pulse and exercise performance. This suggests that

\begin{tabular}{|c|c|c|c|c|}
\hline & IC $/$ TLC $>25 \%$ & $\mathrm{IC} / \mathrm{TLC} \leqslant \mathbf{2 5} \%$ & Difference between means $(95 \% \mathrm{Cl})$ & $\mathrm{p}$-value \\
\hline Subjects $\mathbf{n}$ & 42 & 45 & & \\
\hline Age yrs & $63 \pm 7$ & $66 \pm 10$ & $-2.8(-6.6-1.0)$ & $0.1^{\#}$ \\
\hline $\mathrm{BMI} \mathbf{k g} \cdot \mathrm{m}^{-2}$ & $27.8(24.6-31.5)$ & $24.9(22.3-26.9)$ & $2.7(0.6-4.8)$ & $0.008^{\circ}$ \\
\hline $\mathrm{FFM}$ index $\mathrm{kg} \cdot \mathrm{m}^{-2}$ & $21 \pm 3$ & $19 \pm 4$ & $1.8(0.02-3.6)$ & $0.04^{\#}$ \\
\hline MMRC & $2(2-3)$ & $2(2-3)$ & $-0.20(-0.54-0.13)$ & $0.3^{*}$ \\
\hline 6MWD m & $415 \pm 91$ & $326 \pm 80$ & $89(52-125)$ & $<0.001^{\#,+}$ \\
\hline Hand grip force $\mathbf{k g}$ & $33.5(26-46)$ & $26(20-36)$ & $8.7(3.8-13.6)$ & $<0.001^{\bullet,+}$ \\
\hline FEV $1 \%$ pred & $36(30-41)$ & 30 (26-39) & $3.9(0.3-7.5)$ & $0.03^{\circ}$ \\
\hline
\end{tabular}

Data with a normal distribution are presented as mean \pm SD and data not normally distributed is presented as median (interquartile range), unless otherwise stated. Cl: confidence interval; BMI: body mass index; FFM: fat-free mass; MMRC: Modified Medical Research Council dyspnoea scale; 6MWD: 6-min walk distance; FEV1: forced expiratory volume in one second; \% pred: \% predicted; FVC: forced vital capacity. ${ }^{\#}$ : comparisons performed using the unpaired t-test; " the Mann-Whitney test; ${ }^{+}$: significant values after using Bonferroni corrections to adjust for multiple comparison. 
TABLE 4 Cardiopulmonary exercise test results in patients with chronic obstructive pulmonary disease grouped according to inspiratory capacity (IC)/total lung capacity (TLC) ratio

\begin{tabular}{|c|c|c|c|c|}
\hline & $\mathrm{IC} / \mathrm{TLC}^{\#}>\mathbf{2 5} \%$ & $\mid \mathrm{IC} / \mathrm{TLC}^{\star} \leqslant \mathbf{2 5 \%}$ & $\begin{array}{l}\text { Difference between means } \\
\qquad(95 \% \mathrm{Cl})\end{array}$ & $\mathrm{p}$-value \\
\hline Exercise power $\mathrm{W}$ & $74(58-100)$ & $49(42-59)$ & $26.5(15.1-37.9)$ & $<0.001^{+, \S}$ \\
\hline \multicolumn{5}{|l|}{$\mathrm{V}^{\prime} \mathrm{O}_{2}$} \\
\hline Baseline $L \cdot \mathrm{min}^{-1}$ & $0.218(0.175-0.27)$ & $0.194(0.156-0.276)$ & $0.016(-0.022-0.045)$ & $0.2^{+}$ \\
\hline Maximal L.min ${ }^{-1}$ & $0.802(0.610-1.150)$ & $0.547(0.456-0.734)$ & $0.245(0.097-0.394)$ & $<0.001^{+, \S}$ \\
\hline Baseline beats $\cdot \mathrm{min}^{-1}$ & $82 \pm 15$ & $91 \pm 14$ & $-9(-16--2)$ & $0.01^{f}$ \\
\hline Maximal beats $\cdot \mathrm{min}^{-1}$ & $122 \pm 18$ & $120 \pm 14$ & $2(-5,9)$ & $0.5^{f}$ \\
\hline$\%$ pred & $78 \pm 12$ & $78 \pm 8$ & $-0.4(-5-4)$ & $0.8^{f}$ \\
\hline Anaerobic threshold ${ }^{\# \#} \%$ & $42 \pm 11$ & $35 \pm 6$ & $7.2(-0.1-14.6)$ & $0.05^{f}$ \\
\hline \multicolumn{5}{|l|}{$\mathrm{O}_{2}$ pulse } \\
\hline Baseline $\mathrm{mL} \cdot$ beat $^{-1}$ & $2.8 \pm 0.9$ & $2.3 \pm 0.8$ & $0.3(-0.03-0.8)$ & $0.07^{f}$ \\
\hline Peak L & $1.46 \pm 0.38$ & $1.05 \pm 0.33$ & $0.4(0.2-0.6)$ & $<0.001^{+, \S}$ \\
\hline$\Delta \mathrm{L}$ & $0.62 \pm 0.50$ & $0.32 \pm 0.30$ & $0.3(0.1-0.5)$ & $<0.003^{\S, f}$ \\
\hline \multicolumn{5}{|l|}{ IC/TLC } \\
\hline Peak \% & $21(18-24)$ & $14(11-19)$ & $6.5(4-9)$ & $<0.001^{+, \S}$ \\
\hline$\Delta \%$ & $8(5-12)$ & $4.2(2.2-7.5)$ & $4(1.6-6.5)$ & $<0.001^{+, \S}$ \\
\hline
\end{tabular}

hyperinflation at rest is as important as peak exercise hyperinflation as a predictor of exercise performance in patients with severe COPD.

In patients with COPD, an IC/TLC ratio $\leqslant 25 \%$, an indicator of severe static hyperinflation, has been associated with reduced exercise capacity and increased mortality $[26,27]$. There have been no previous studies analysing the relationship between IC/TLC and cardiac performance. The current study explored this relationship and has shown that IC/TLC was directly

TABLE 5 Multivariate analysis in the chronic obstructive pulmonary disease group with oxygen pulse at peak exercise as the dependent variable

\begin{tabular}{lccc}
$\begin{array}{l}\text { Independent } \\
\text { variable }\end{array}$ & Coefficient & p-value & $\begin{array}{c}\text { Standardised } \\
\text { coefficients }\end{array}$ \\
\hline BMI $\mathbf{~ g g} \cdot \mathbf{m}^{-2}$ & 0.133 & 0.002 & 0.275 \\
IC/TLC $\%$ & 0.090 & 0.013 & 0.247 \\
FEV $1 \%$ pred & 0.073 & 0.008 & 0.239 \\
Hand grip force $\mathbf{~ k g}$ & 0.096 & $<0.001$ & 0.462 \\
\hline
\end{tabular}

BMI: body mass index; IC: inspiratory capacity; TLC: total lung capacity; FEV1: forced expiratory volume in one second; \% pred: \% predicted. The $y$-axis intercept value was $-0.5377 . r^{2}=0.60$

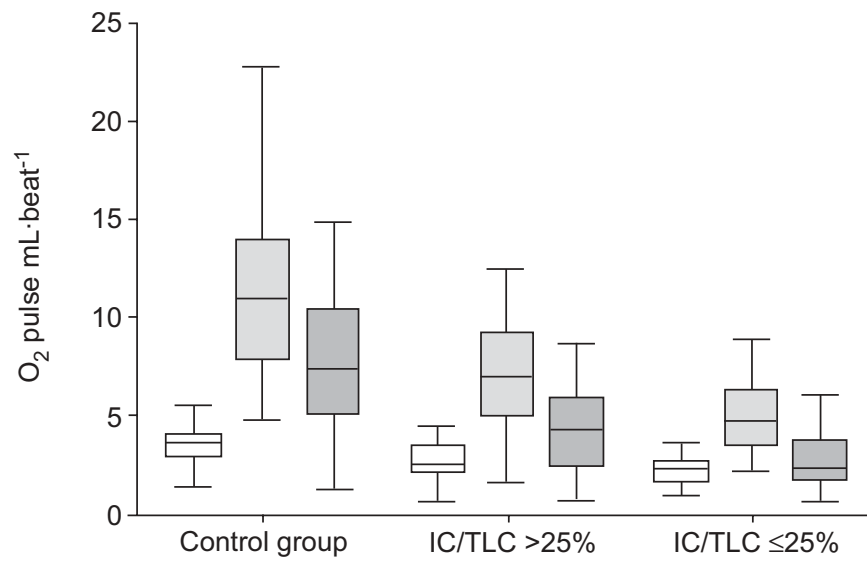

FIGURE 4. Oxygen pulse in controls, patients with chronic obstructive pulmonary disease (COPD) and inspiratory capacity (IC)/total lung capacity (TLC) ratio $>25 \%$ and $I C / T L C \leqslant 25 \%$ shown as median and interquartile range. The oxygen pulse is shown at rest $(\square)$, at peak exercise $(\square)$ and the change in oxygen pulse from rest to peak exercise $(\square)$ for all groups. Compared with controls patients with severe COPD had lower oxygen pulse at rest and blunted increase in oxygen pulse with exercise. Patients with more severe hyperinflation (IC/TLC $\leqslant 25 \%$ ) had significantly lower oxygen pulse at rest and even more blunted oxygen pulse response with exercise than patients with less hyperinflation. Kruskal-Wallis test $p<0.001$. Control group: $n=46$; IC/TLC $>25 \%$ : $n=42 ; I C / T L C \leqslant 25 \%: n=45$. 

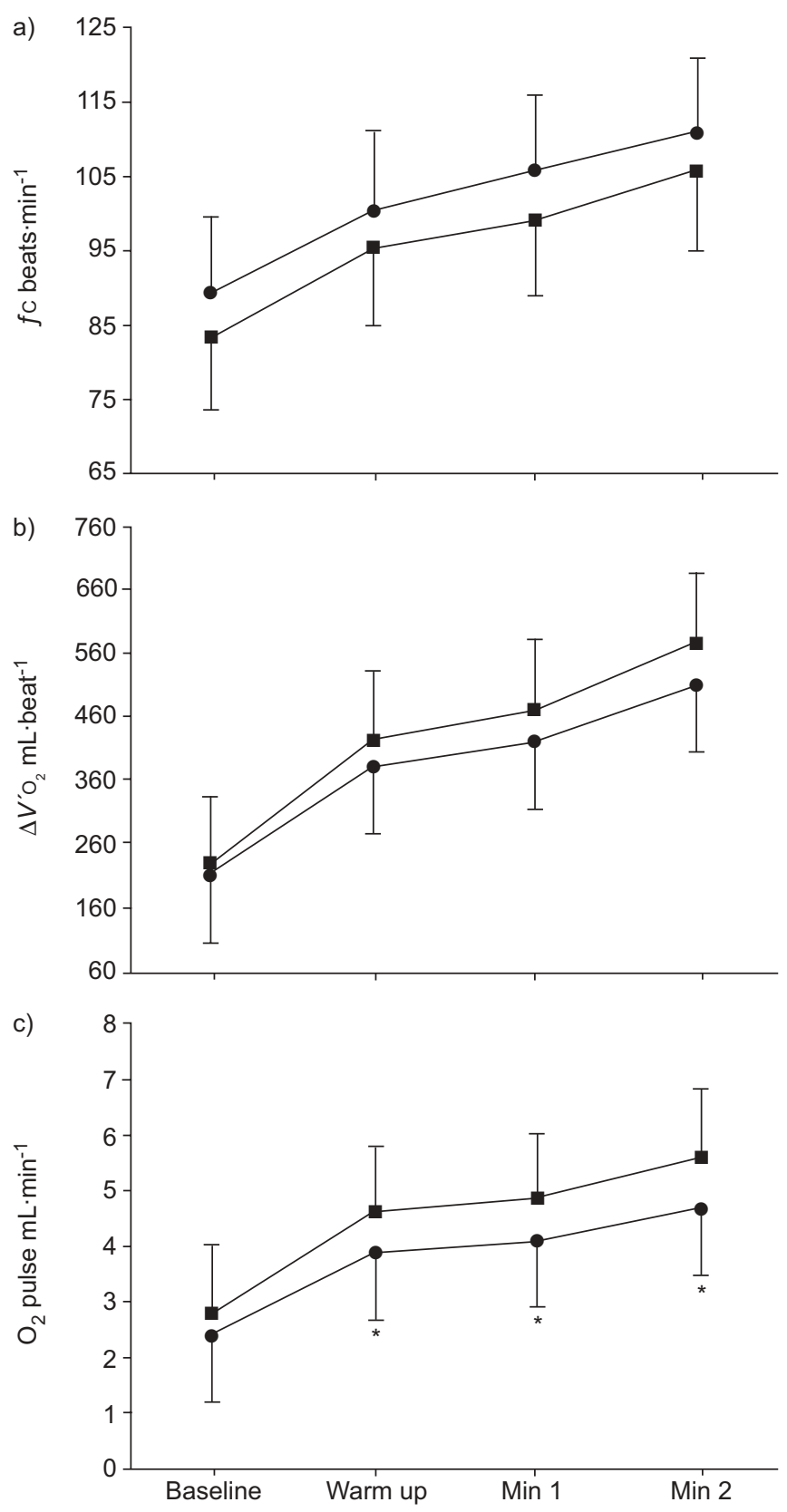

FIGURE 5. At iso-time and similar workload, the oxygen pulse (c) failed to increase in patients with inspiratory capacity (IC)/total lung capacity (TLC) ratio $\leqslant 25 \%(\boldsymbol{n}=45,26$ males) compared with the increase observed in patients with IC/TLC >25\% ( $\mathbf{\square} ; n=42,27$ males). The difference was due to (a) faster cardiac capacity $(f C)$ and $b)$ lower oxygen uptake $\left(V^{\prime} \mathrm{O}_{2}\right)$ at all time points. *: $p<0.05$ between IC/TLC $>25 \%$ and $\leqslant 25 \%$.

associated with oxygen pulse. Patients with low IC/TLC $(\leqslant 25 \%)$ at rest had a lower baseline oxygen pulse, a blunted increase in oxygen pulse with exercise (fig. 5) and a decrease in exercise capacity $\left(\mathrm{W}, V^{\prime} \mathrm{O}_{2} \mathrm{~L} \cdot \mathrm{min}^{-1}, V^{\prime} \mathrm{O}_{2} \mathrm{~mL} \cdot \mathrm{kg}^{-1} \cdot \mathrm{min}\right)$ compared with those with an IC/TLC $>25 \%$ and with normal controls. This suggests that patients with lower IC/TLC may already have impaired cardiac function, even at rest. The present finding is supported by the work of JöRGENSEN et al. [19] who, using direct haemodynamic monitoring, demonstrated that patients with severe COPD who underwent LVRS had a $40 \%$ improvement in cardiac index, $34 \%$ in stroke volume index and $55 \%$ in stroke work index at rest after the surgery. JÖRGENSEN et al. [18], using magnetic resonance techniques in 13 patients with severe COPD compared with eleven matched volunteers, have also shown a significant reduction in enddiastolic volume of the right and left ventricles at rest in the patients with COPD. Although they postulated that hyperinflation could be the cause of the decreased heart size and volume, they did not measure hyperinflation and its effect during exercise. The present findings extend these observations by showing that, even at rest, the level of hyperinflation affects the oxygen pulse. Dynamic hyperinflation can further impair cardiac function either by decreasing blood return to the right heart or by increasing the afterload to the left ventricle due to increase intra-thoracic pressure swings, as suggested by MONTES DE OCA et al. [35]. Both factors may be playing a role in a manner similar to that reported in mechanically ventilated patients with ventilator-induced hyperinflation and development of hypotension from compromised heart function.

Hyperinflation may interact with the heart via intrathoracic pressure changes that are larger in the most hyperinflated patients [35]. In fact, the mean IC at rest in the group of patients with IC/TLC $\leqslant 25 \%$ is lower than the peak exercise IC observed in the patients with an IC/TLC $>25 \%$ (table 4 ). This indicates that the level of hyperinflation in the low IC/TLC group is quite severe and places significant constraints on the operational volume that can be recruited at rest and more so as exercise demands increase. It is likely that patients with this degree of resting hyperinflation cannot increase inflation further due to the anatomical and physiological constraints of the lungs and chest wall. This observation is in agreement with that of O'DONNELL et al. [3] who have reported that patients with the smaller IC at rest are those who recruit IC the least during exercise. Thus, normal subjects do not change IC because they do not hyperinflate, while patients with moderate obstruction and IC/TLC $>25 \%$ have room to hyperinflate, manifesting larger $\Delta \mathrm{IC}$. Patients with the most severe obstruction and hyperinflation (IC/TLC $\leqslant 25 \%$ ) do not have room to increase IC, and thus, like normal patients, would have low $\Delta \mathrm{IC}$. This explains why in $\Delta \mathrm{IC}$ had a modest correlation with $\Delta \mathrm{O}_{2}$ pulse (fig. 2), whereas in a good correlation was seen between absolute IC and oxygen pulse at the same workload (fig. 3). Patients unable to recruit operational lung volume are forced to increase intrathoracic pressures in an attempt to increase ventilation. This can in turn increase the pressure in the cardiac fossa with its consequences on heart function [17, 18]. Further support for the influence of lung volume on heart function is provided by the study by TRAVERS et al. [36] who observed decreased $f C$ at similar work in patients randomised to tiotropium. The patients on tiotropium had decreased operational volumes when compared with placebo, possibly placing less mechanical strain on the heart [36].

The present authors recognise that the oxygen pulse does not directly measure stroke volume but it is a good surrogate marker of it. In a recent study of patients with COPD by RIETEMA et al. [37], measurements of cardiac function (including stroke volume) with central catheter and magnetic resonance during exercise had an excellent correlation. Interestingly, the oxygen pulse values obtained at peak exercise were very similar to the 
ones reported in the current study. This, coupled with the data from other studies of patients with COPD [4, 20-25], provides increasing evidence in support of the oxygen pulse as a surrogate marker of stroke volume in patients with COPD. The current study also assessed the other factors influencing arterial blood oxygen content. According to WASSERMAN et al. [20], the oxygen pulse is not affected in patients with an arterial oxygen content $>15 \mathrm{~mL}$. The average arterial oxygen content of the present patients was $17.9 \pm 2.0 \mathrm{~mL}$ at peak exercise, well above the cited oxygen content threshold, thus making it unlikely that the low oxygen pulse measurement was due to low oxygen content. It has been suggested that in patients with severe COPD the oxygen extraction is decreased during exercise [25]. This implies that the difference in arterial versus venous oxygen content is lower and may minimise its effect on oxygen pulse. Recent data obtained from direct access to the femoral artery and vein of exercising patients and matched controls show that the oxygen extraction is similar in both groups $[4,25]$. This was also seen in patients with different degree of airflow limitation [4]. Whether the oxygen extraction is similar or lower in COPD during exercise [24], these differences cannot account for the decrease in oxygen pulse, since a lower difference would actually magnify the oxygen pulse value. The arterial blood oxygen content is also influenced by the $\mathrm{Pa}_{\mathrm{a}} \mathrm{O}_{2}$, with values $<55 \mathrm{mmHg}(<7.3 \mathrm{kPa})$ decreasing the content and potentially influencing the oxygen pulse results. To exclude that factor as the possible determinant of the low oxygen pulse in the present study, it was evaluated whether the association of IC/TLC to oxygen pulse was maintained in patients with a rest and peak exercise $\mathrm{Pa}, \mathrm{O}_{2}>55 \mathrm{mmHg}(>7.3 \mathrm{kPa})$. This group of patients had appropriate oxygen saturation throughout the exercise and hence hypoxemia with a concomitant decrease in the arterial oxygen content could not have contributed to the decrease in oxygen pulse.

It is interesting to note that the peak total work (in W) was statistically lower $(\mathrm{p}<0.001)$ in patients with IC/TLC $\leqslant 25 \%$ compared with patients with IC/TLC $>25 \%$. It was evident from the current data that the amount of work was directly associated with the oxygen pulse $(r=0.87)$. This is in agreement with the findings of others $[3,11]$ who have observed decreased exercise capacity in more hyperinflated patients.

The strong direct association of IC/TLC and work $(r=0.69)$ and with oxygen pulse extends the present findings and supports the argument that the decrease in exercise capacity can at least in part be attributed to decreased stroke volume secondary to the effects of hyperinflation on cardiac function.

The strongest support for an effect of hyperinflation on stroke volume is provided by the lower oxygen pulse documented at similar time points and workload in the patients with lower IC/TLC (fig. 5). The current analysis shows that the lower oxygen pulse was not due to the lower workload that hyperinflated patients are capable of achieving but that at similar workload, the hyperinflated patients cannot increase oxygen supply.

In multivariate analysis, the IC/TLC was an independent predictor of oxygen pulse. There was also an association between oxygen pulse with hand grip strength, which is intriguing. It is possible that the reduced grip strength is related to diffuse muscle weakness in patients with decreased muscle mass (FFM index was lower in patients with IC/TLC $\leqslant 25 \%$ ). The current authors wonder if the heart muscle mass is also affected in patients with severe COPD. The present authors do know that patients with the most severe COPD have important muscle compromise but, to date, there have been no studies aimed at evaluating intrinsic cardiac muscle fibre strength in patients with COPD. Patients with worse COPD may also suffer from dysautonomic cardiac regulation, a fact that is supported by the faster $f C$ at rest and during exercise in patients with IC/TLC $\leqslant 25 \%$. Further studies are needed to explore these different mechanisms.

The most important limitation of the present study is the lack of direct measurement of the cardiac output using a pulmonary artery catheter. However, it is an invasive measurement that is not without complications and is technically difficult during exercise; several studies support the validity of the oxygen pulse as a surrogate marker of stroke volume in patients with COPD $[4,20,25]$. A second limitation is that the current study involved only patients with severe COPD. However, patients were selected with more severe airflow obstruction in order to have enough power to detect changes related to IC/TLC as those are the patients likely to develop hyperinflation during exercise. A control group was also included with similar anthropometric characteristics that did not show hyperinflation and provided the basic comparison for reference oxygen pulse values. Finally, the clinical implications of the present observations remain to be determined. However, the results by JörGENSON et al. [19] suggest that one possible group that may potentially benefit from lung reduction surgery is those patients with low IC/TLC whose oxygen pulse fails to increase with exercise.

In conclusion, the present results show that resting hyperinflation, associated with dynamic increase in end-expiratory lung volume, seems to play an important role in limiting exercise in patients with chronic obstructive pulmonary disease via its effect on cardiac function, as suggested by a relatively low oxygen pulse at rest and its incapacity to increase adequately during exercise in patients with worse hyperinflation. It is likely that therapy that improves resting lung volume and hyperinflation improves exercise capacity, at least in part, by improving cardiac function.

\section{REFERENCES}

1 Celli BR, MacNee W. Standards for the diagnosis and treatment of patients with COPD: a summary of the ATS/ ERS position paper. Eur Respir J 2004; 23: 932-946.

2 Diaz O, Villafranca C, Ghezzo H, et al. Role of inspiratory capacity on exercise tolerance in COPD patients with and without tidal expiratory flow limitation at rest. Eur Respir J 2000; 16: 269-275.

3 O'Donnell DE, Revill SM, Webb KA. Dynamic hyperinflation and exercise intolerance in chronic obstructive pulmonary disease. Am J Respir Crit Care Med 2001; 164: 770-777.

4 Simon M, LeBlanc P, Jobin J, Desmeules M, Sullivan MJ, Maltais F. Limitation of lower limb $V^{\prime} \mathrm{O}_{2}$ during cycling exercise in COPD patients. J Appl Physiol 2001; 90: 1013-1019. 
5 Gosselink R, Troosters T, Decramer M. Peripheral muscle weakness contributes to exercise limitation in COPD. Am J Respir Crit Care Med 1996; 153: 976-980.

6 Medoff BD, Oelberg DA, Kanarek DJ, Systrom DM. Breathing reserve at the lactate threshold to differentiate a pulmonary mechanical from cardiovascular limit to exercise. Chest 1998; 113: 913-918.

7 Casaburi R. Factors determining constant work rate exercise tolerance in COPD and their role in dictating the minimal clinically important difference in response to interventions. COPD 2005; 2: 131-136.

8 Martinez FJ, de Oca MM, Whyte RI, Stetz J, Gay SE, Celli BR. Lung-volume reduction improves dyspnoea, dynamic hyperinflation, and respiratory muscle function. Am J Respir Crit Care Med 1997; 155: 1984-1990.

9 Pellegrino R, Brusasco V, Rodarte JR, Babb TG. Expiratory flow limitation and regulation of end-expiratory lung volume during exercise. J Appl Physiol 1993; 74: 2552-2558.

10 Celli B, ZuWallack R, Wang S, Kesten S. Improvement in resting inspiratory capacity and hyperinflation with tiotropium in COPD patients with increased static lung volumes. Chest 2003; 124: 1743-1748.

11 O'Donnell DE, Voduc N, Fitzpatrick M, Webb KA. Effect of salmeterol on the ventilatory response to exercise in chronic obstructive pulmonary disease. Eur Respir J 2004; 24: 86-94.

12 LoRusso TJ, Belman MJ, Elashoff JD, Koerner SK. Prediction of maximal exercise capacity in obstructive and restrictive pulmonary disease. Chest 1993; 104: 17481754.

13 Tschernko EM, Gruber EM, Jaksch P, et al. Ventilatory mechanics and gas exchange during exercise before and after lung volume reduction surgery. Am J Respir Crit Care Med 1998; 158: 1424-1431.

14 Bauerle O, Chrusch CA, Younes M. Mechanisms by which COPD affects exercise tolerance. Am J Respir Crit Care Med 1998; 157: 57-68.

15 Carlson DJ, Ries AL, Kaplan RM. Prediction of maximum exercise tolerance in patients with COPD. Chest 1991; 100: 307-311.

16 Celli BR, Frants R. Circulatory effects of COPD. In: Scharf SM, Pinsky MR, Magder S, eds. Respiratory-Circulatory Interactions in Health and Disease. New York, Marcel Dekker, Inc., 2001; pp. 681-703.

17 Butler J, Schrijen F, Henriquez A, Polu JM, Albert RK. Cause of the raised wedge pressure on exercise in chronic obstructive pulmonary disease. Am Rev Respir Dis 1988; 138: 350-354.

18 Jörgensen K, Müller MF, Nel J, Upton RN, Houltz E, Ricksten SE. Reduced intrathoracic blood volume and left and right ventricular dimensions in patients with severe emphysema: an MRI study. Chest 2007; 131: 1050-1057.

19 Jörgensen K, Houltz E, Westfelt U, Nilsson F, Scherstén H, Ricksten SE. Effects of lung volume reduction surgery on left ventricular diastolic filling and dimensions in patients with severe emphysema. Chest 2003; 124: 1863-1870.
20 Wasserman K, Hansen JE, Sue DY, Stringer WW, Whipp BJ. Principles of Exercise Testing and Interpretation. 4th Edn. Philadelphia, Lippincott Williams and Wilkins, 2005.

21 Crisafulli A, Piras F, Chiappori P, et al. Estimating stroke volume from oxygen pulse during exercise. Physiol Meas 2007; 28: 1201-1212.

22 Aliverti A, Dellaca RL, Lotti P, et al. Influence of expiratory flow-limitation during exercise on systemic oxygen delivery in humans. Eur J Appl Physiol 2005; 95: 229-242.

23 Bhambhani Y, Norris S, Bell G. Prediction of stroke volume from oxygen pulse measurements in untrained and trained men. Can J Appl Physiol 1994; 19: 49-59.

24 Oelberg DA, Kacmarek RM, Pappagianopoulos PP, Ginns LC, Systrom DM. Ventilatory and cardiovascular responses to inspired $\mathrm{He}-\mathrm{O}_{2}$ during exercise in chronic obstructive pulmonary disease. Am J Respir Crit Care Med 1998; 158: 1876-1882.

25 Sala E, Roca J, Marrades RM, et al. Effects of endurance training on skeletal muscle bioenergetics in chronic obstructive pulmonary disease. Am J Respir Crit Care Med 1999; 159: 1726-1734.

26 Casanova C, Cote C, de Torres JP, et al. Inspiratory-to-total lung capacity ratio predicts mortality in patients with chronic obstructive pulmonary disease. Am J Respir Crit Care Med 2005; 171: 591-597.

27 Albuquerque AL, Nery LE, Villaca DS, et al. Inspiratory fraction and exercise impairment in COPD patients GOLD stages II-III. Eur Respir J 2006; 28: 939-944.

28 Minh VD, Lee HM, Vasquez P, Shepard JW, Bell JW. Relation of $\mathrm{VO}_{2}$ max to cardiopulmonary function in patients with chronic obstructive lung disease. Bull Eur Physiopathol Respir 1979; 15: 359-377.

29 Miller MR, Hankinson J, Brusasco V, et al. Standardisation of spirometry. Eur Respir J 2005; 26: 319-338.

30 Wanger J, Clausen JL, Coates A, et al. Standardisation of the measurement of lung volumes. Eur Respir J 2005; 26: 511-522.

31 Macintyre N, Crapo RO, Viegi G, et al. Standardisation of the single-breath determination of carbon monoxide uptake in the lung. Eur Respir J 2005; 26: 720-735.

32 ATS statement, guidelines for the six-minute walk test. Am J Respir Crit Care Med 2002; 166: 111-117.

33 Mathiowetz V, Kashman N, Volland G, Weber K, Dowe M, Rogers S. Grip and pinch strength: normative data for adults. Arch Phys Med Rehab 1985; 66: 69-74.

34 ATS/ACCP statement on cardiopulmonary exercise testing, Am J Respir Crit Care Med 2003; 167: 211-277.

35 Montes de Oca M, Rassulo J, Celli BR. Respiratory muscle and cardiopulmonary function during exercise in very severe COPD. Am J Respir Crit Care Med 1996; 154: 1284-1289.

36 Travers J, Laveneziana P, Webb KA, Kesten S, O'Donnell DE. Effect of tiotropium bromide on the cardiovascular response to exercise in COPD. Respir Med 2007; 101: 2017-2024.

37 Rietema H, Holverda S, Bogaard HJ, et al. Sildenafil treatment in COPD does not affect stroke volume or exercise capacity. Eur Respir J 2008; 31: 759-764. 